\title{
Outcome of Atrial Septal Defects versus Ventricular Septal Defects in Response to Bosentan Treatment: Proof of Concept Controlled Study in Pulmonary Arterial Hypertension Related to Eisenmenger Syndrome
}

\author{
Kritvikrom Durongpisitkul ${ }^{1 *}$, Paweena Chungsomprasong ${ }^{1}$, Rungroj Krittayaphong ${ }^{2}$ and Suree Sompradeekul $^{3}$ \\ ${ }^{1}$ Division of Cardiology, Department of Pediatrics, Faculty of medicine, Siriraj Hospital, Mahidol University, Bangkok, Thailand \\ ${ }^{2}$ Division of Cardiology, Faculty of medicine, Siriraj Hospital, Mahidol University, Bangkok, Thailand \\ ${ }^{3}$ Division of Pulmonary Medicine, Department of Internal Medicine, Faculty of medicine, Siriraj Hospital, Mahidol University, Bangkok, Thailand
}

\section{Abstract}

Background: Bosentan was shown to have benefit for treatment of patients with Eisenmenger (ES) with some data showing hemodynamic deterioration in patients with Atrial Septal Defect (ASD) than in Ventricular Septal Defect (VSD).

Method: A proof of concept study was designed to evaluate effect of bosentan treatment for 12 months using both clinical outcome and Cardiac Magnetic Resonance (CMR).

Results: Ten patients were enrolled with average age of $39.7 \pm 9.7$ years. There were 5 ASD and 5 VSD in each group. There is no statistical significance in baseline data among both groups. During the follow up period there is an improvement of 6 Minute Walk Distance (6 MWD) at 4 months, but the effect levels off at 12 months. Patients with VSD group showed better improvement of 6 MWD more than in ASD group ( $p=0.52$ at 4 months and $p=0.009$ at 12 months). All CMR findings were not statistically different at 12 months. However, patients who had VSD showed significant improvement in RV EF from baseline of $54.6 \pm 14.5 \%$ to $56.27 \pm 13.79 \%$ and $57.53 \pm 7.66 \%$ when compared to ASD of $38.3 \pm 11.5 \%$ to $38.72 \pm 10.55 \%$ and $39.24 \pm 10.80 \%$ at 4 months and 12 months respectively $(p=0.025)$.

Conclusion: We demonstrated improvement of 6 MWD in ES with bosentan treatment for 12 months. We were not able to show improvement in CMR parameter at 12 months, however, when compared, VSD group had significant improvement in RVEF to ASD group.

\section{Introduction}

Eisenmenger Syndrome (ES) is defined as Congenital Heart Disease (CHD) with an initial large systemic-to-pulmonary shunt that induced progressive pulmonary vascular disease and Pulmonary Arterial Hypertension (PAH), and resulting in reversal of previous left to right shunt leads to clinical cyanosis and chronic hypoxemia. Most ES patients survive into adulthood with a reported 3-year survival rate of 77\% [1]. Progressive Right Ventricular (RV) failure remains the main cause of mortality in these patients [1-5].

An oral dual endothelin receptor antagonist, bosentan, was shown to significantly improve exercise capacity, decrease Pulmonary Vascular Resistance index (PVRi) without compromising oxygen saturation (SpO2) in patients with ES [6]. The Open-Label Extension study (OLE) showed the efficacy and safety of bosentan after 40 weeks of treatment [7] (BREATH5-OLE). Previous studies used 6-minute walk distance (6 MWD) and hemodynamic data from Right Heart Catheterization (RHC) to evaluate the efficacy of bosentan. In a subgroup analysis of BREATH-5 patients, the observed data also suggested that placebotreated patients with atrial septal defect (ASD) may have experienced a greater hemodynamic deterioration from baseline than placebo-treated patients in the ventricular septal defect (VSD) subgroup [8].

In this proof of concept study, we aimed to assess the outcome of bosentan treated patients with ES comparing among those who had ASD and VSD. We hypothesized that using cardiac magnetic resonance imaging (CMR) as additional surrogate end point will be able to differentiate the outcome among both groups of patients. In addition, this study will also examine changes in oxygen saturation, exercise capacity measured by 6 MWD as well as measures of functional status as secondary endpoints. We also evaluated the predictor for bosentan responders, for example, age, level of pulmonary artery pressure, severity of structural change of the RV such as RV mass, RV End Diastolic Volume (RVEDV), and RV function.

\section{Design and Methods}

\section{Patients}

ES patients (defined as congenital heart disease with evidence of high PVR and right to left shunting from previous cardiac catheterization), aged over 18 years old, had body weight more than $35 \mathrm{~kg}$ and had WHO functional less than class III were enrolled in this prospective study. All of them had oxygen saturation between $70 \%$ and $95 \%$ (at rest with room air). Their clinical symptoms were stable for at least 3 months prior to screening and all of them were naive to endothelin receptor antagonist. They received an initial dosing phase (administration of bosentan $62.5 \mathrm{mg}$ twice a day for 4 weeks), followed by an up-titration treatment phase (bosentan $125 \mathrm{mg}$ twice a day). Change of medication was prohibited during the study period. All patients underwent 6-minute walk test at baseline, 4 months and 1 year after treatment. Cardiac magnetic resonance imaging was also undergone at baseline, 4 months, and 12 months after treatment. This study was approved

*Corresponding author: Kritvikrom Durongpisitkul, MD, Department of Pediatrics, Faculty of Medicine, Siriraj Hospital, Mahidol University, Bangkok 10700, Thailand, Tel: (66-02) 4196824; Fax: (66-02) 419-7000 E-mail: sikdr@mahidol.ac.th, kritvikrom@gmail.com

Received December 16, 2011; Accepted April 13, 2012; Published April 15, 2012

Citation: Durongpisitkul K, Chungsomprasong P, Krittayaphong R, Sompradeekul S (2012) Outcome of Atrial Septal Defects versus Ventricular Septal Defects in Response to Bosentan Treatment: Proof of Concept Controlled Study in Pulmonary Arterial Hypertension Related to Eisenmenger Syndrome. J Pulmon Resp Med 2:120. doi:10.4172/2161-105X.1000120

Copyright: () 2012 Durongpisitkul K, et al. This is an open-access article distributed under the terms of the Creative Commons Attribution License, which permits unrestricted use, distribution, and reproduction in any medium, provided the original author and source are credited. 
Citation: Durongpisitkul K, Chungsomprasong P, Krittayaphong R, Sompradeekul S (2012) Outcome of Atrial Septal Defects versus Ventricular Septal Defects in Response to Bosentan Treatment: Proof of Concept Controlled Study in Pulmonary Arterial Hypertension Related to Eisenmenger Syndrome. J Pulmon Resp Med 2:120. doi:10.4172/2161-105X.1000120

Page 2 of 5

by Siriraj Ethic Committee. Informed consents from all patients were given before participation.

\section{Cardiac magnetic resonance imaging $(\mathrm{CMR})$}

CMR was performed using a Gyroscan NT 1.5 Tesla, (Philips) with prospective ECG gating during repeated breath-holds. After scout imaging was performed, a steady-state balanced FFE sequence, $8.0 \mathrm{~mm}$. slice thickness and 10-12 segments per heart beat, was used to acquire functional imaging of the heart. Standard long-axis views and shortaxis views were obtained. A stack of short-axis slices allows calculation of the left and right ventricular mass, volume, and ejection fraction.

\section{Delayed contrast enhancement}

Delayed contrast enhanced images were acquired by copying the image position for each of the short-axis slices as for cine images, 10 15 minutes after the administration of $0.2 \mathrm{mmol} / \mathrm{kg}$ of gadolinium (Magnevist, Schering). Endocardial and epicardial borders were manually traced. Hyperenhanced regions were manually contoured on

\begin{tabular}{|c|c|c|c|c|}
\hline \multirow[t]{2}{*}{ Variables } & \multicolumn{4}{|c|}{ Results } \\
\hline & Total $(\mathrm{N}=10)$ & $\begin{array}{l}\text { ASD group } \\
(\mathrm{N}=5)\end{array}$ & $\begin{array}{l}\text { VSD group } \\
(\mathrm{N}=5)\end{array}$ & $P$ value \\
\hline Age (year) & $39.7 \pm 9.7$ & $43 \pm 11.0$ & $36.2 \pm 7.7$ & 0.279 \\
\hline Gender (male : female) & $1: 9$ & $0: 5$ & $1: 4$ & 0.347 \\
\hline Weight (kilograms) & $45.0 \pm 9.0$ & $48.5 \pm 10.9$ & $41.5 \pm 5.9$ & 0.244 \\
\hline Oxygen saturation; $\mathrm{SaO} 2(\%)$ & $82.6 \pm 8.9$ & $83.2 \pm 8.1$ & $81.9 \pm 6.9$ & 0.833 \\
\hline Hemoglobin; Hb (g/dl) & $17.6 \pm 2.0$ & $16.3 \pm 1.8$ & $18.7 \pm 1.5$ & 0.048 \\
\hline $\begin{array}{l}\text { Mean pulmonary arterial } \\
\text { pressure; mPAP }(\mathrm{mmHg})\end{array}$ & $77.2 \pm 14.6$ & & & \\
\hline$(54-95)$ & $64.1 \pm 98$ & $61 \pm 11.4$ & 0.582 & \\
\hline $\begin{array}{l}\text { Pulmonary vascular resis- } \\
\text { tance; Rpa (dyne.sec.cm-5) }\end{array}$ & $\begin{array}{c}2,768.7 \pm \\
1,769.5\end{array}$ & & & \\
\hline$(724-6168)$ & $2,568 \pm 2,174$ & $3,018 \pm 1,378$ & 0.731 & \\
\hline $\begin{array}{l}\text { Six-minute walk distance; } \\
\text { 6MWD (meters) }\end{array}$ & $275 \pm 42.0$ & $288 \pm 33.6$ & $261 \pm 50.6$ & 0.347 \\
\hline NT-proBNP level (pg/ml) & $\begin{array}{l}731.7 \pm \\
919.0\end{array}$ & $926 \pm 1135$ & $537 \pm 733$ & 0.535 \\
\hline \multicolumn{5}{|l|}{ WHO Functional class } \\
\hline -III (cases) & 6 & 4 & 2 & 0.242 \\
\hline -IV (cases) & 4 & 1 & 3 & \\
\hline
\end{tabular}

Table 1: Demographic data at baseline in all patients (Total), atrial septal defect (ASD) and ventricular septal defect (VSD) groups. each short-axis slice. Delayed contrast enhanced area was shown as a total area $\left(\mathrm{mm}^{2}\right)$, and a percentage of total (left plus right ventricular) myocardial area.

\section{Plasma brain natriuretic peptide (BNP)}

Plasma Brain Natriuretic Peptide (BNP) is secreted by ventricular myocardium in response to ventricular strain and cleaved into the inactive N-terminal proBNP (NT-proBNP) and the active BNP [9]. $\mathrm{BNP}$ is elevated in various form of $\mathrm{PAH}$ including idiopathic $\mathrm{PAH}$ (iPAH), PAH associated with interstitial lung disease, with congenital systemic-to-pulmonary shunts, with chronic obstructive pulmonary disease, and in chronic thromboembolic pulmonary hypertension [10]. NT-pro-BNP is highly stable in plasma and has been described as a marker of pulmonary hypertension in patients with systemic sclerosis [11] more recently iPAH [12]. This study will also examine changes in NT-proBNP levels as a measure of RV stress [13], at baseline as well as throughout a 16 week treatment period with bosentan. This study also examined changes in NT-proBNP levels (as a measure of RV stress), at baseline as well as throughout a 1 year treatment period with bosentan.

\section{Liver function test}

Regarding bosentan affected liver function, the patients whose Aspartate Aminotransferase (AST) and/or Alanine Aminotransferase (ALT) elevated more than 3 times of normal limit were excluded.

\section{Statistical analyses}

Data was analyzed with SPSS for Windows (Version 15). Continuous data was expressed as frequency or mean \pm the Standard Deviation (SD) or median with range. Comparisons in $6 \mathrm{MWD}$ and oxygen saturation among baseline, 4 months, and 12 months after treatment period with bosentan were analyzed with ANOVA test. The following CMR variables were analyzed with ANOVA or Friedman test when appropriate: LVEDV index, LV mass index, LV stroke volume index (LVSVi), LVEF, RVEDV index, RV mass index, RV stroke volume index (RVSVi), RVEF, total myocardial scar, and scar percentage index (\% scar index). A P value of $<0.05$ was considered statistically significant.

\section{Results}

Patient characteristics and hemodynamic data from previous cardiac catheterization are shown in Table 1 . Ten patients were enrolled with average age of $39.7 \pm 9.7$ years. There were 5 ASD and 5 VSD in

\begin{tabular}{|c|c|c|c|c|c|c|c|c|c|c|c|c|c|}
\hline \multirow[t]{2}{*}{ Variables } & \multicolumn{4}{|c|}{ baseline } & \multicolumn{4}{|c|}{4 months } & \multicolumn{4}{|c|}{12 months } & \multirow{2}{*}{$\begin{array}{c}\text { P- } \\
\text { value* }^{*}\end{array}$} \\
\hline & ASD group & VSD group & Total & $p$ value & ASD group & VSD group & Total & $p$ value & ASD group & VSD group & Total & $p$ value & \\
\hline FC & $3.2 \pm 0.45$ & $3.6 \pm 0.55$ & $3.4 \pm 0.52$ & 0.242 & $2.8 \pm 0.45$ & $3 \pm 0$ & $2.9 \pm 0.32$ & 0.347 & $2.8 \pm 0.45$ & $2.8 \pm 0.45$ & $2.8 \pm 0.42$ & 1.0 & 0.16 \\
\hline $\begin{array}{l}6 \text { minute } \\
\text { walk dis- } \\
\text { tance }(\mathrm{m})\end{array}$ & $288.96 \pm 33.69$ & $261.82 \pm 50.61$ & $\begin{array}{c}290.11 \pm \\
65.34\end{array}$ & 0.347 & $\begin{array}{c}304.0 \pm \\
35.07\end{array}$ & $\begin{array}{c}306.0 \pm \\
66.39\end{array}$ & $\begin{array}{l}305 \pm \\
50.07\end{array}$ & 0.94 & $\begin{array}{c}294.0 \pm \\
32.86\end{array}$ & $323.2 \pm 23.69$ & $\begin{array}{c}325.1 \pm \\
40.64\end{array}$ & 0.146 & 0.126 \\
\hline $\begin{array}{l}\text { The Borg } \\
\text { dyspnea } \\
\text { index }\end{array}$ & $2.6 \pm 1.14$ & $3.6 \pm 0.89$ & $3.1 \pm 1.1$ & 0.161 & $1.6 \pm 2.04$ & $2.1 \pm 1.24$ & $1.85 \pm 1.61$ & 0.653 & $0.5 \pm 0.5$ & $1.2 \pm 0.75$ & $0.93 \pm 0.72$ & 0.21 & 0.546 \\
\hline $\begin{array}{l}\text { Hemoglo- } \\
\text { bin (g/dl) }\end{array}$ & $16.36 \pm 1.77$ & $18.78 \pm 1.49$ & $\begin{array}{c}17.57 \pm \\
2.00\end{array}$ & 0.51 & $16.44 \pm 1.50$ & $18.90 \pm 1.42$ & $\begin{array}{c}17.67 \pm \\
1.89\end{array}$ & 0.6 & $15.92 \pm 1.60$ & $19.92 \pm 0.71$ & $\begin{array}{c}17.92 \pm \\
2.41\end{array}$ & 0.06 & 0.726 \\
\hline $\begin{array}{l}\text { NT-proBNP } \\
\text { (pg/dl) }\end{array}$ & $924.4 \pm 112.5$ & $537.00 \pm 733.69$ & $\begin{array}{c}731.70 \pm \\
918.98\end{array}$ & 0.53 & $\begin{array}{l}537.0 \pm \\
864.93\end{array}$ & $\begin{array}{l}442.0 \pm \\
448.02\end{array}$ & $\begin{array}{c}599 \pm \\
670.19\end{array}$ & 0.49 & $\begin{array}{l}391.8 \pm \\
348.15\end{array}$ & $\begin{array}{l}446.0 \pm \\
690.18\end{array}$ & $\begin{array}{c}418.90 \\
\pm 516.14\end{array}$ & 0.879 & 0.497 \\
\hline AST (iU/L) & $24.6 \pm 7.36$ & $24.8 \pm 7.25$ & $24.7 \pm 6.89$ & 0.96 & $24.6 \pm 7.26$ & $22.8 \pm 6.3$ & $\begin{array}{c}23.70 \pm \\
6.48\end{array}$ & 0.68 & $22.2 \pm 2.77$ & $26.4 \pm 7.73$ & $\begin{array}{c}37.00 \pm \\
5.90\end{array}$ & 0.28 & 0.910 \\
\hline ALT (iU/L) & $13.8 \pm 3.76$ & $16.8 \pm 7.01$ & $15.30 \pm 5.54$ & 0.428 & $20.8 \pm 11.43$ & $16.6 \pm 6.76$ & $\begin{array}{c}18.7 \pm \\
9.13\end{array}$ & 0.5 & $15.0 \pm 4.06$ & $21 \pm 9.5$ & $\begin{array}{c}18.00 \pm \\
7.59\end{array}$ & 0.23 & 0.487 \\
\hline
\end{tabular}

NT-pro BNP: N-terminal pro brain natriuretic peptide, AST: aspartate aminotransferance: ALT: alanine aminotransrerase, $p$-value ${ }^{*}$ was among total group, $p$-value was among subgroup, all were compared at baseline, 4 months and 12 months.

Table 2: Clinical and laboratory results at baseline, 4-month, and 12-month study period. 
Citation: Durongpisitkul K, Chungsomprasong P, Krittayaphong R, Sompradeekul S (2012) Outcome of Atrial Septal Defects versus Ventricular Septal Defects in Response to Bosentan Treatment: Proof of Concept Controlled Study in Pulmonary Arterial Hypertension Related to Eisenmenger Syndrome. J Pulmon Resp Med 2:120. doi:10.4172/2161-105X.1000120

Page 3 of 5

each group. All had severe pulmonary arterial hypertension with mean pulmonary arterial pressure of $77.22 \pm 14.6 \mathrm{mmHg}$ and mean pulmonary vascular resistance (Rpa) of 2,768.71 $\pm 1,769.5$ dyne.sec.cm5. All of them had cyanosis from right to left shunt with mean oxygen saturation of $82.55 \pm 8.9 \%$. No patient died in the study period.

\section{Clinical outcome (Table 2)}

During follow-up period, mean 6-minute walk distance of all patients improved from a baseline distance of $290.11 \pm 65.34$ meters to $325.10 \pm 40.64$ meters (improvement 35 meters). This improvement was explicit by 4 months of treatment (improvement 54 meters) in most of patients and was sustained during the 12-month study period. The changed $6 \mathrm{MWD}$ in total group did not significantly improve, $32 \pm 59.09$ meters at 4 months $(\mathrm{p}=0.112)$ and $3.3 \pm 46.26$ meters at 12 months $(\mathrm{p}=0.827)$. We found differences in 6 MWD among each subgroup. While the VSD group had a trend towards improvement of $6 \mathrm{MWD}$ at 4 months and one year $(40 \pm 75$ meters, $42 \pm 26$ meters respectively), the ASD group had an improvement of 6 MWD at 4 months but declined at 12 months (15.04 \pm 34 meters, $-10 \pm 17$ meters respectively). The $6 \mathrm{MWD}$ at 12 months was significantly improved in VSD group, when compared with the ASD group, $(\mathrm{P}=0.009)$ as shown in Figure 1. The Borg dyspnea index were $3.1 \pm 1.1,1.85 \pm 1.61$, and 0.93

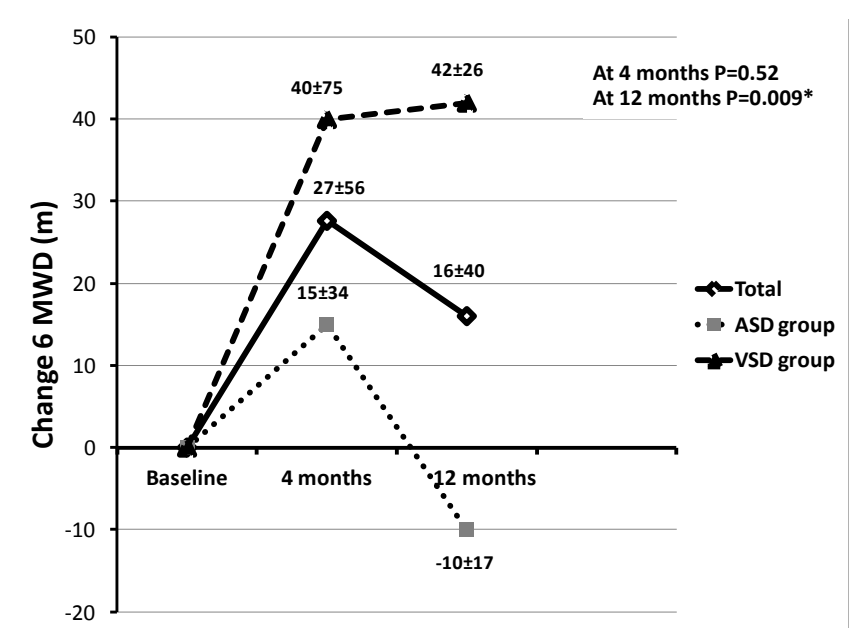

Figure 1: Incremental change of six minute walk distance (6 MWD) from baseline to 4 months and to 12 months of total group, Atrial septal defect group (ASD) and ventricular septal defect group (VSD). Numbers were shown in mean \pm S.D. \pm 0.72 at baseline, 4 months and 12 months after treatment $(\mathrm{p}=0.546)$ Two patients had improvement of WHO functional class from class III to class II (ASD 1, VSD 1) and four patients from class IV to III (ASD 4, VSD 1). The remainders had no change of WHO functional class. There was no deterioration of mean oxygen saturation from baseline to 4-month, and 12-month study period (82.6 $\pm 8.9,83.0 \pm 7.8$, and 82.5 $\pm 9.96 \%$, respectively)

\section{Laboratory results (Table 2)}

Level of NT-proBNP at baseline was elevated in all patients. Although there were a trend toward decreasing of NT- proBNP level at 4 months and 12 months, this was not statistically significant ( $\mathrm{p}=0.497)$. Concerning of adverse effect of bosentan, liver enzyme value (AST and ALT) at both 4-month and 12-month study period were also similar with baseline of treatment.

\section{Cardiac magnetic resonance (CMR)}

At baseline, there were abnormal CMR findings as shown in Table 3. We analyzed RVEDV index, RV End Systolic Volume (ESV) index, and RV stroke volume index that were increased from normal. CMR variables showed no statistical significance from baseline to 4-month and 12-month study period between baseline and 4-month of bosentan treatment as shown in Table 3. Although there is no difference in RVEF from baseline to 4 months and 12 months, however, in subgroup comparison, VSD patients showed a significant improving in RVEF when compared to ASD patients $(\mathrm{p}=0.025)$ as shown in Table 4 . Total myocardial scar (Figure 2) and percentage of scar did not significantly change after treatment

\section{Discussion}

ES is the most advanced form of PAH that will deteriorate with longer period. Bosentan is one of the specific treatment that improves or maintains exercise capacity [6,7] 6 MWD and quality of life [14]. Although, overall $6 \mathrm{MWD}$ and the Borg dyspnea index in this study have tendency to be improved with time, but there were no significant changes in both 6 MWD and the Borg score over 12 months. The previous study showed the improvement after bosentan treatment ( $33.2 \pm 23.9 \mathrm{~m}$ in ex- placebo and $61.3 \pm 8.0 \mathrm{~m}$ in ex- bosentan group) [7]. Thus, clinical symptoms of these patients could be improved after bosentan administration. Most of our patients had stable WHO functional class signified that bosentan could improve exercise capacity. No deterioration of oxygen saturation suggested that bosentan could limit the progression of right to left shunt, which worsen with times in

\begin{tabular}{|c|c|c|c|c|}
\hline Variables & Baseline & 4 months & 12 months & $P$ value \\
\hline LVEDV index & $60.75 \pm 19.98$ & $65.28 \pm 24.84$ & $63.61 \pm 22.04$ & 0.241 \\
\hline LV mass index (g/m2) & $46.21 \pm 13.01$ & $45.24 \pm 13.09$ & $45.43 \pm 13.70$ & 0.715 \\
\hline LVESV index & $25.95 \pm 17.40$ & $27.26 \pm 18.43$ & $24.78 \pm 16.06$ & 0.176 \\
\hline LVSV index & $34.80 \pm 6.04$ & $37.99 \pm 7.69$ & $38.44 \pm 7.37$ & 0.308 \\
\hline LVEF (\%) & $60.86 \pm 14.86$ & $61.87 \pm 12.44$ & $63.80 \pm 10.35$ & 0.498 \\
\hline RVEDV index & $112.70 \pm 57.98$ & $112.05 \pm 61.36$ & $112.68 \pm 60.53$ & 0.958 \\
\hline RV mass index (g/m2) & $50.58 \pm 17.56$ & $47.05 \pm 16.97$ & $48.78 \pm 16.61$ & 0.066 \\
\hline RVESV index & $67.40 \pm 48.93$ & $65.96 \pm 50.70$ & $64.89 \pm 48.09$ & 0.717 \\
\hline RVSV index & $45.30 \pm 11.07$ & $46.10 \pm 13.44$ & $47.78 \pm 15.81$ & 0.663 \\
\hline RVEF (\%) & $45.53 \pm 14.80$ & $46.52 \pm 14.58$ & $47.37 \pm 13.16$ & 0.506 \\
\hline Total myocardial scar (mm2) & $1,355.50 \pm 696.12$ & $1,243.72 \pm 621.96$ & $1,229.70 \pm 640.06$ & 0.399 \\
\hline$\%$ scar index $(\% / m 2)$ & $5.71 \pm 2.48$ & $5.43 \pm 2.48$ & $5.54 \pm 2.74$ & 0.657 \\
\hline
\end{tabular}

LVEDV: left ventricular end diastolic volume, LV: left ventricle, LVESV: left ventricular end systolic volume, LVSV: left ventricular stroke volume, LVEF: left ventricular ejection fraction, RVEDV: right ventricular end diastolic volume, RV: right ventricle, RVESV: right ventricular end systolic volume, RVSV: right ventricular stroke volume, RVEF: right ventricular ejection fraction

Table 3: demonstrated CMR data when compared at baseline, 4 month and 12 month of treatment ( $\mathrm{P}$ value $<0.05$ *signifies statistical significance). 
Citation: Durongpisitkul K, Chungsomprasong P, Krittayaphong R, Sompradeekul S (2012) Outcome of Atrial Septal Defects versus Ventricular Septal Defects in Response to Bosentan Treatment: Proof of Concept Controlled Study in Pulmonary Arterial Hypertension Related to Eisenmenger Syndrome. J Pulmon Resp Med 2:120. doi:10.4172/2161-105X.1000120

Page 4 of 5

patients with ES. These findings were similar to previous study $[6,7,15-$ $18]$.

Since RV structure and function play a major role in diagnosis and follow-up of patients with PAH. Cardiac magnetic resonance (CMR) imaging is a useful tool in the evaluation of RV morphology, RV systolic function (ejection fraction), cardiac output and myocardial scar [1921]. Published data shows good correlation between Ventricular Mass Index (VMI) and mean Pulmonary Arterial Pressure (mPAP) including delay contrast enhanced images [22]. Delayed Contrast Enhancement (DCE) is a well-established marker of myocardial abnormalities. For ES, DCE was mainly observed at the RV insertion point, a region of a particular mechanical stress [23].

There was one study that showed RV end-diastolic volume index (RVDEVi), Stroke Volume (SV), and Left Ventricular End-Diastolic Volume (LVEDV) were strong independent predictors of mortality and treatment failure in patients with pulmonary hypertension [2]. The extent of the delayed contrast enhancement was related with mPAP, pulmonary hemodynamic and was inversely correlated with RV function [23], suggesting that delayed contrast enhancement might be useful for prediction of prognosis in pulmonary hypertension.

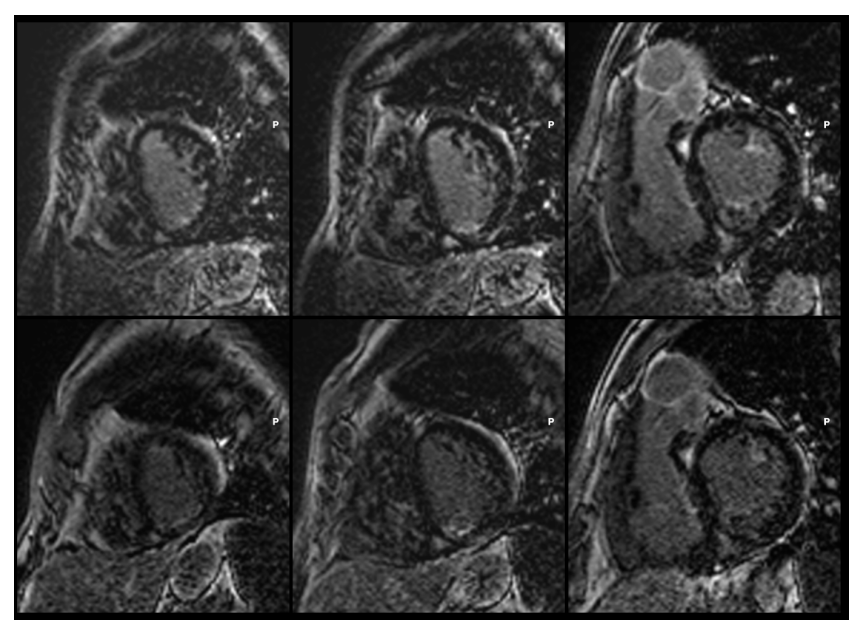

Figure 2: Short-axis view from still frames of cardiac Magenetic resonance Imaging of one patient at base line (top) and at the end of 6 months (buttom) showed myocardial delay contrast enhancement (DCE) involving various area of enhancement and at septal right ventricular insertion points (arrow). There was no significant change in area of DCE during both periods.
In our study, RV mass index after treatment with bosentan had a tendency to decrease in early phase of treatment and similar to result of BREATH-5. However, RV mass index at 12-month study period did not continue to decrease. As a result, there was no significant difference after 12 -month period ( $\mathrm{p}=0.066$ ). RVEDV index, RVSV, RVEF and LVEF were also not significant statistic improved after 12 month study period. Due to the progression of this disease with times, RV stroke volume, which correlated inversely with pulmonary vascular resistance [24], should decrease in patients without treatment. So, it could be concluded that our patients did not deteriorate as the natural history of this disease.

Associated cardiac lesion resulted in prognosis of the patient with pulmonary hypertension $[25,26]$. Even though, one study reported that bosentan treatment did not significantly improve in the pulmonary arterial hypertension patients with atrial septal defect (ASD) and with ventricular septal defect (VSD) [8]. We divided our patients into two groups; ASD and VSD group. Interestingly, the improvement of six minute walk test at 12 months in VSD group was significant improved when compared with the ASD group $-10 \pm 17$ vs $42 \pm 26$ meters $(\mathrm{p}=0.009)$. In addition, RV mass index, RVEDV, RV and LV stroke volume were not different between the ASD and VSD group, however, only RVEF in the VSD group was significantly improved from baseline of $54.6 \pm 14.5 \%$ to $56.27 \pm 13.79 \%$ and $57.53 \pm 7.66 \%$ when compared to ASD from baseline of $38.3 \pm 11.5 \%$ to $38.72 \pm 10.55 \%$ and 39.24 $\pm 10.80 \%$ at 4 months and 12 months respectively $(\mathrm{p}=0.025)$. In ES patients, worsening of RV systolic function was expected over time. The treatment in general was aimed at preserved (non-worsening) of RV systolic function. Measuring of RV EF by cardiac MRI was proven to be accurate and highly reliable. We believed that both groups showed certain improvement of RV function by non-worsening of RV EF, however, effect was seen more in VSD patients.

This data also showed the significant advantage of bosentan to improve the outcome of Eisenmenger patient in patients who had VSD when compared to ASD both 6 MWD and RVEF. Patients with VSD did not have loading of pressure and volume loading begins during early period of ES [8]. As a result, RVEF might be affected later in the patients with VSD which may lead to favorable long term outcome.

\section{Conclusion}

Even though, bosentan could be benefit for Eisenmenger patients including clinical symptom and RV remodeling, it led in different results of each groups, ASD and VSD group. Cardiac MRI also can be one of

\begin{tabular}{|c|c|c|c|c|c|c|c|c|c|}
\hline Variables & Baseline & 4 months & 12 months & & & & & & \\
\hline & ASD & VSD & $P$ value & ASD & VSD & $P$ value & ASD & VSD & $P$ value \\
\hline LVEDV index & $55.5 \pm 12.2$ & $67.3 \pm 27.6$ & 0.413 & $56.52 \pm 15.78$ & $76.22 \pm 32.01$ & 0.263 & $56.37 \pm 12.17$ & $72.65 \pm 30.00$ & 0.30 \\
\hline LV mass index $(\mathrm{g} / \mathrm{m} 2)$ & $44.9 \pm 10.2$ & $47.8 \pm 23$ & 0.763 & $41.78 \pm 6.65$ & $49.61 \pm 18.76$ & 0.407 & $39.98 \pm 6.75$ & $52.22 \pm 18.13$ & 0.2 \\
\hline LVESV index & $20.7 \pm 6.3$ & $34.9 \pm 4.6$ & 0.348 & $21.44 \pm 10.17$ & $34.52 \pm 25.31$ & 0.321 & $18.65 \pm 7.34$ & $3.00 \pm 21.8$ & 0.22 \\
\hline LVSV index & $37.7 \pm 6.3$ & $34.8 \pm 4.6$ & 0.348 & $35.09 \pm 7.63$ & 41.616 .94 & 0.227 & $37.0 \pm 6.94$ & $40.23 \pm 8.51$ & 0.549 \\
\hline LVEF (\%) & $64.4 \pm 15.2$ & $56.3 \pm 15.3$ & 0.453 & $63.9 \pm 11.39$ & $59.32 \pm 14.97$ & 0.617 & $67.42 \pm 7.44$ & $59.27 \pm 12.74$ & 0.26 \\
\hline RVEDV index & $143.2 \pm 60$ & $74.6 \pm 26.0$ & 0.073 & $144.37 \pm 63.41$ & $71.65 \pm 27.56$ & 0.072 & $144.31 \pm 58.69$ & $73.12 \pm 37.71$ & 0.075 \\
\hline $\mathrm{RV}$ mass index $(\mathrm{g} / \mathrm{m} 2)$ & $1.2 \pm 0.4$ & $1.0 \pm 0.4$ & 0.426 & $1.25 \pm 0.34$ & $0.86 \pm 0.35$ & 0.14 & $50.43 \pm 14.07$ & $46.71 \pm 21.48$ & 0.76 \\
\hline RVESV index & $92.2 \pm 51.7$ & $36.3 \pm 22.6$ & 0.086 & $91.8 \pm 53.81$ & $33 . .64 \pm 22.11$ & 0.085 & $90.39 \pm 48.87$ & $33.00 \pm 23.32$ & 0.07 \\
\hline RVSV index & $50.9 \pm 11.8$ & $38.2 \pm 4.5$ & 0.087 & $52.57 \pm 14.38$ & $38.0 \pm 6.95$ & 0.108 & $53.92 \pm 15.35$ & $40.09 \pm 14.52$ & 0.26 \\
\hline RVEF (\%) & $38.3 \pm 11.5$ & $54.6 \pm 14.5$ & 0.101 & $38.72 \pm 10.55$ & $56.27 \pm 13.79$ & 0.066 & $39.24 \pm 10.80$ & $57.53 \pm 7.66$ & $0.025^{*}$ \\
\hline Total myocardial scar (mm2) & $1,275.4 \pm 522.8$ & $1,435.6 \pm 894.9$ & 0.738 & $1,327.86 \pm 606.69$ & $1,159.58 \pm 696.13$ & 0.811 & $1,277.54 \pm 605.31$ & $1,181.86 \pm 741.38$ & 0.83 \\
\hline$\%$ scar index $(\% / \mathrm{m} 2)$ & $5.6 \pm 3.2$ & $5.9 \pm 1.9$ & 0.87 & $5.77 \pm 3.13$ & $5.09 \pm 1.93$ & 0.693 & $920.27 \pm 488.13$ & $1181.86 \pm 741.38$ & 0.97 \\
\hline
\end{tabular}

LVEDV: left ventricular end diastolic volume, LV: left ventricle, LVESV: left ventricular end systolic volume, LVSV: left ventricular stroke volume, LVEF: left ventricular ejection fraction, RVEDV: right ventricular end diastolic volume, RV: right ventricle, RVESV: right ventricular end systolic volume, RVSV: right ventricular stroke volume, RVEF: right ventricular ejection fraction

Table 4: demonstrated CMR data when compared in subgroup at baseline, 4 month and 12 month of treatment $(P$ value $<0.05$ *signifies statistical significance). 
Citation: Durongpisitkul K, Chungsomprasong P, Krittayaphong R, Sompradeekul S (2012) Outcome of Atrial Septal Defects versus Ventricular Septal Defects in Response to Bosentan Treatment: Proof of Concept Controlled Study in Pulmonary Arterial Hypertension Related to Eisenmenger Syndrome. J Pulmon Resp Med 2:120. doi:10.4172/2161-105X.1000120

the tools to evaluate of RV function that depends on the underlining disease in each patient. After bosentan administration, 6 MWD was significantly improved in VSD group when compared to ASD group. Cardiac MRI demonstrated the significantly statistic improvement of RVEF in VSD group when compared with ASD group.

\section{References}

1. Hopkins WE, Ochoa LL, Richardson GW, Trulock EP (1996) Comparison of the hemodynamics and survival of adults with severe primary pulmonary hypertension or Eisenmenger syndrome. J Heart Lung Transplant 15: 100-105.

2. van Wolferen SA, Marcus JT, Boonstra A, Marques KM, Bronzwaer JG, et al. (2007) Prognostic value of right ventricular mass, volume, and function in idiopathic pulmonary arterial hypertension. Eur Heart J 28: 1250-1257.

3. Sitbon O, Humbert M, Nunes H, Parent F, Garcia G, et al. (2002) Longterm intravenous epoprostenol infusion in primary pulmonary hypertension: prognostic factors and survival. J Am Coll Cardiol 40: 780-788.

4. Raymond RJ, Hinderliter AL, Willis PW, Ralph D, Caldwell EJ, et al. (2002) Echocardiographic predictors of adverse outcomes in primary pulmonary hypertension. J Am Coll Cardiol 39: 1214-1219.

5. Bustamante-Labarta M, Perrone S, De La Fuente RL, Stutzbach P, De La Hoz $\mathrm{RP}$, et al. (2002) Right atrial size and tricuspid regurgitation severity predict mortality or transplantation in primary pulmonary hypertension. J Am Soc Echocardiogr 15: 1160-1164.

6. Galiè N, Beghetti M, Gatzoulis MA, Granton J, Berger RM, et al. (2006) Bosentan therapy in patients with Eisenmenger syndrome: a multicenter, double-blind, randomized, placebo-controlled study. Circulation 114: 48-54.

7. Gatzoulis MA, Beghetti M, Galiè N, Granton J, Berger RM, et al. (2008) Longerterm bosentan therapy improves functional capacity in Eisenmenger syndrome: results of the BREATHE-5 open-label extension study. Int J Cardiol 127: 27-32.

8. Berger RM, Beghetti M, Galiè N, Gatzoulis MA, Granton J, et al. (2010) Atrial septal defects versus ventricular septal defects in BREATHE-5, a placebocontrolled study of pulmonary arterial hypertension related to Eisenmenger's syndrome: a subgroup analysis. Int J Cardiol 144: 373-378.

9. Yasue H, Yoshimura M, Sumida H, Kikuta K, Kugiyama K, et al. (1994) Localization and mechanism of secretion of B-type natriuretic peptide in comparison with those of A-type natriuretic peptide in normal subjects and patients with heart failure. Circulation 90: 195-203.

10. Park MH, Scott RL, Uber PA, Ventura HO, Mehra MR (2004) Usefulness of B-type natriuretic peptide as a predictor of treatment outcome in pulmonary arterial hypertension. Congest Heart Fail 10: 221-225.

11. Mukerjee D, Yap LB, Holmes AM, Nair D, Ayrton P, et al. (2003) Significance of plasma N-terminal pro-brain natriuretic peptide in patients with systemic sclerosis-related pulmonary arterial hypertension. Respir Med 97: 1230-1236.

12. Souza R, Jardim C, Julio Cesar Fernandes C, Silveira Lapa M, Rabelo R, et al. (2007) NT-proBNP as a tool to stratify disease severity in pulmonary arterial hypertension. Respir Med 101: 69-75.

13. Nagaya N, Nishikimi T, Okano Y, Uematsu M, Satoh T, et al. (1998) Plasma brain natriuretic peptide levels increase in proportion to the extent of righ ventricular dysfunction in pulmonary hypertension. J Am Coll Cardiol 31: 202208

14. Strange G, Keogh AM, Williams TJ, Wlodarczyk J, McNeil KD, et al. (2008) Bosentan therapy in patients with pulmonary arterial hypertension: the relationship between improvements in 6 minute walk distance and quality of life. Respirology 13: 674-682

15. Apostolopoulou SC, Manginas A, Cokkinos DV, Rammos S (2007) Long-term oral bosentan treatment in patients with pulmonary arterial hypertension related to congenital heart disease: a 2-year study. Heart 93: 350-354.

16. D'Alto M, Vizza CD, Romeo E, Badagliacca R, Santoro G, et al. (2007) Long term effects of bosentan treatment in adult patients with pulmonary arterial hypertension related to congenital heart disease (Eisenmenger physiology): safety, tolerability, clinical, and haemodynamic effect. Heart 93: 621-625.

17. Christensen DD, McConnell ME, Book WM, Mahle WT (2004) Initial experience with bosentan therapy in patients with the Eisenmenger syndrome. Am J Cardiol 94: 261-263.

18. Apostolopoulou SC, Manginas A, Cokkinos DV, Rammos S (2005) Effect of the oral endothelin antagonist bosentan on the clinical, exercise, and haemodynamic status of patients with pulmonary arterial hypertension related to congenital heart disease. Heart 91: 1447-1452.

19. Boxt LM, Katz J, Kolb T, Czegledy FP, Barst RJ (1992) Direct quantitation of right and left ventricular volumes with nuclear magnetic resonance imaging in patients with primary pulmonary hypertension. J Am Coll Cardiol 19: 15081515.

20. McLure LE, Peacock AJ (2007) Imaging of the heart in pulmonary hypertension. Int J Clin Pract Suppl 156: 15-26.

21. Katz J, Whang J, Boxt LM, Barst RJ (1993) Estimation of right ventricular mass in normal subjects and in patients with primary pulmonary hypertension by nuclear magnetic resonance imaging. J Am Coll Cardiol 21: 1475-1481.

22. Saba TS, Foster J, Cockburn M, Cowan M, Peacock AJ (2002) Ventricular mass index using magnetic resonance imaging accurately estimates pulmonary artery pressure. Eur Respir J 20: 1519-1524.

23. Blyth KG, Groenning BA, Martin TN, Foster JE, Mark PB, et al. (2005) Contrast enhanced-cardiovascular magnetic resonance imaging in patients with pulmonary hypertension. Eur Heart J 26: 1993-1999.

24. Chin KM, Kingman M, de Lemos JA, Warner JJ, Reimold S, et al. (2008) Changes in right ventricular structure and function assessed using cardiac magnetic resonance imaging in bosentan-treated patients with pulmonary arterial hypertension. Am J Cardiol 101: 1669-1672.

25. Simonneau G, Robbins IM, Beghetti M, Channick RN, Delcroix M, et al. (2009) Updated clinical classification of pulmonary hypertension. J Am Coll Cardio 54: S43-S54.

26. Engelfriet PM, Duffels MG, Möller T, Boersma E, Tijssen JG, et al. (2007) Pulmonary arterial hypertension in adults born with a heart septal defect: the Euro Heart Survey on adult congenital heart disease. Heart 93: 682-687. 